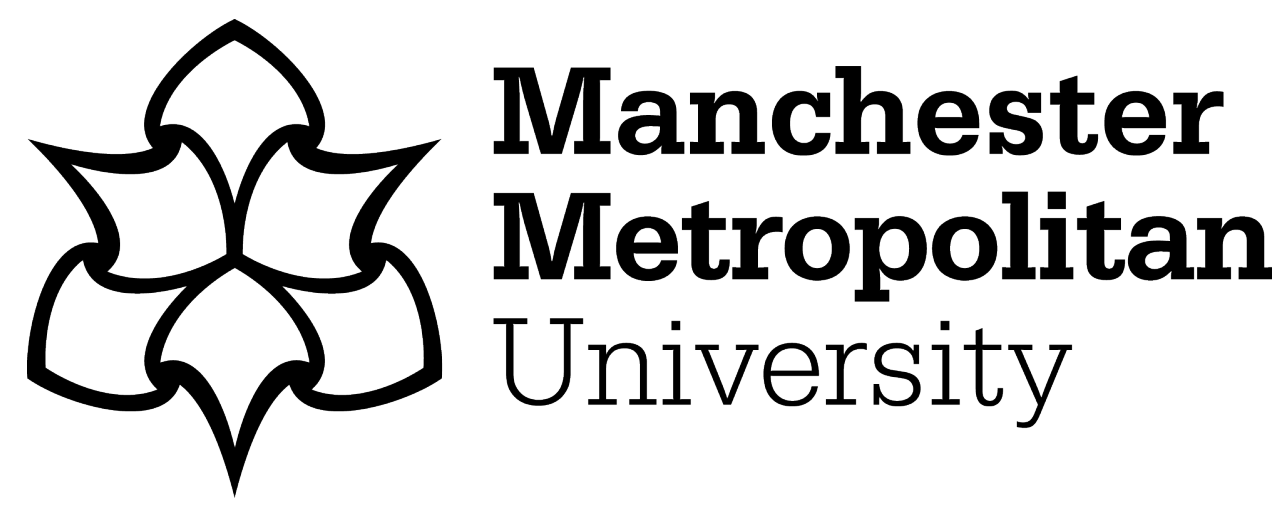

Silva, TCG, Anholon, R, Rampasso, IS, Quelhas, OLG, Leal Filho, W, SantaEulalia, LA and Lima Junior, FR (2022) Evaluation of the integration level of quality and environmental management systems in a tire manufacturer. The TQM Journal, 34 (4). pp. 770-787. ISSN 1754-2731

Downloaded from: https://e-space.mmu.ac.uk/628148/

Version: Accepted Version

Publisher: Emerald

DOI: https://doi.org/10.1108/TQM-12-2020-0293

Please cite the published version 


\title{
Evaluation of the integration level of quality and environmental management systems in a tire manufacturer
}

\author{
TQM Journal 01 Jan 2021
}

https://www.emerald.com/insight/content/doi/10.1108/TQM-12-2020-0293/full/html

Silva, Thais Coutinho Gonçalves ${ }^{\mathrm{a}}$; Anholon, Rosley ${ }^{\mathrm{b}}$; Rampasso, Izabela Simon ${ }^{\mathrm{c}}$; Quelhas, Osvaldo Luiz Gonçalves ${ }^{\mathrm{d}}$; Leal Filho, Walter ${ }^{\mathrm{e} *}$; Santa-Eulalia, Luis Antoniof; Lima Junior, Francisco Rodrigues ${ }^{\mathrm{g}}$

${ }^{a}$ School of Mechanical Engineering, University of Campinas. Mendeleyev Street, 200, Campinas, Brazil. Email: thais_coutinho@yahoo.com;

${ }^{\mathrm{b}}$ School of Mechanical Engineering, University of Campinas. Mendeleyev Street, 200, Campinas, Brazil. Email: rosley@fem.unicamp.br;

'School of Mechanical Engineering, University of Campinas. Mendeleyev Street, 200, Campinas, Brazil; Laboratory of Technology, Business and Environment Management, Federal Fluminense University. Passo da Pátria Street, 156, Niterói, Brazil. Email: izarampasso@gmail.com;

${ }^{\mathrm{d}}$ Laboratory of Technology, Business and Environment Management, Federal Fluminense University. Passo da Pátria Street, 156, Niterói, Brazil. Email: osvaldoquelhas@id.uff.br

${ }^{e}$ Faculty of Life Sciences, Hamburg University of Applied Sciences. Ulmenliet 20, D21033, Hamburg, Germany. Email: walter.leal2@haw-hamburg.de;

fÉcole de gestion, Université de Sherbrooke. 2500, boul. de l'Université, J1K 2R1, Sherbrooke, Canada. Email: Luis.Antonio.De.Santa-Eulalia@usherbrooke.ca;

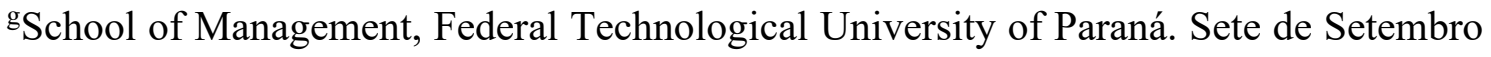
Avenue, 3165, Curitiba, Brazil. Email: eng.franciscojunior@gmail.com. 


\begin{abstract}
Due to the increasing importance of Integrated Management Systems for companies competitiveness, this article aims to evaluate the integration level of a quality management system and environmental management system in a tire manufacturer and propose a guide to evaluate the integration of these systems in companies. The methodological strategies used in the research were literature review, for the theoretical foundation; case study, for a better understanding of the company's reality and to verify professionals' perception about benefits arising from some level of integration. Respondents scored the benefits observed and the data were analysed through Technique for Order of Preference by Similarity to Ideal Solution (TOPSIS). The results showed that the studied company has a simple level of integration, observing only some low intensity benefits. Thus, it was recommended that the company partially integrate its management systems before evolving into something more complex. The experiences throughout the study and the information presented in the literature made it possible to develop a guide, in an exploratory character. Lessons learned throughout the study and the suggested guide can help other companies assess the integration level of their quality and environmental management systems. The notable difference of the suggested guide is associated with the combination of information presented by literature, case study, interview procedures and TOPSIS data analysis, presented in an exploratory character. Thus, the findings presented here can be useful for researchers and market professionals.
\end{abstract}

Keywords: Integrated Management Systems; Environmental Management Systems; Quality Management Systems; TOPSIS technique; Manufacturing companies.

\title{
1. Introduction
}

The increasing competition among companies requires a continuous improvement in their management system. In this sense, the integration of companies' management systems can be an important source of competition (Blasco-Torregrosa et al., 2019; Borges et al., 2018; Hassan et al., 2019; Ikram et al., 2020). Among these management systems, the focused on quality (ISO 9001) and environment (ISO 14001) are the standards with the most number of certifications from the International Organization for Standardization worldwide (ISO, 2019). And their integration can generate several benefits (Bernardo et al., 2015; Ikram et al., 2020).

The synergy between these standards can be cited as an important enabler of this integration. Goyal et al. (2019) highlight the role of quality management system (QMS) 
for reduction of negative environmental impacts. Hamdoun et al. (2018) mention the role of QMS as a precursor of an Environment Management System (EMS) due to the similarities among them and the consequent possibility to integrate both management systems.

In order to maximize the results, it is necessary to optimize the existing management systems. However, the difficulties to integrate management systems challenge companies. The need to integrate management systems in companies began to be necessary after the publication of the ISO 14001 standard, in 1996. Since the ISO 14001 publication, companies needed to manage two systems with different scopes, one focusing on environmental practices and the other focusing on quality management practices (Bernardo et al., 2009; Dahlin and Isaksson, 2017; Karapetrovic and Casadesús, 2009; Salomone, 2008). Today, three decades later, many other management systems coexist in companies, such as occupational health and safety (OHSAS 18001/ISO 45001), corporate social responsibility (SA 8000), information security (ISO 27001), energy (ISO 50001) and supply chains (ISO 28000), among others. The need for integration became increasingly evident, making the Integrated Management System (IMS) concept notorious in academic research (Bernardo et al., 2009; Gianni et al., 2017; Karapetrovic and Casadesús, 2009; Salomone, 2008; Shah et al., 2019), especially in a higher education context (Leal Filho et al., 2015).

There are many possible definitions for IMS. According to Bernardo et al. (2010, p. 487), IMS is "a set of interconnected processes that share human resources, information, material, infrastructure and financial resources in order to achieve a combination of goals related to the stakeholder's satisfaction". Also for Bernardo et al. (2009), an IMS seeks to link different Management Systems (MSs) into a single one, in favour of the stakeholder's objectives. Clearly, there are many similarities among different management systems, especially in terms of structure, dissemination process, common standard language and the vision of continuous improvement based on the PDCA cycle.

In this sense, the integration can generate several benefits for companies: minimization of documentation and records, less bureaucracy and information redundancies, reduction of costs, and simplification of internal and external audits, among others (Bernardo et al., 2015; Casadesús et al., 2011; Ikram et al., 2019; Karapetrovic and Casadesús, 2009; Shah et al., 2019). Bernardo et al. (2015) present a complete list of 
internal and external benefits that can be achieved by companies when they incorporate an IMS. Despite the relevance of IMS, there are several gaps about the theme in the literature. Among these gaps, the integration level of companies' management systems can be highlighted (Nunhes and Oliveira, 2018). In addition, differences among countries are also highlighted in the literature (Cabecinhas et al., 2018).

The integration of QMS and Environmental Management Systems (EMS) is not a new topic in research literature. However, this subject still generates interesting debates (Hassan et al., 2019; Hernandez-Vivanco et al., 2019; Ikram et al., 2020; Nunhes et al., 2019). Additionally, the literature fails in providing a guide for companies to evaluate the integration of their QMS and EMS with a quantitative approach. Considering this context, the main objective of this article is to evaluate the integration level of the QMS and EMS in a large tire manufacturer and to propose guidelines for companies to evaluate their quality and environmental management systems. More than a case study, this article presents findings and a guide in an exploratory way that can be used by other companies. Next section presents the theoretical background.

\section{Theoretical Background}

\subsection{Integrated Management Systems}

IMS was defined by Bernardo et al. (2015) and Shah et al. (2019) as the combination of different management systems with specific functions into a single and more effective system. It is associated with the concept of synergy, in which the integration of several elements maximizes the qualities of each element as well as the result. IMS minimizes duplicate tasks, increasing companies' competitive advantages, via resource use optimization (Nunhes et al., 2016). In another definition proposed by Karapetrovic (2003), an IMS is considered a set of interconnected processes that share a single group of employees, information, materials, infrastructure and financial resources to achieve a composition of goals related to the stakeholder's satisfaction.

The multiplicity of stakeholders in the business context contributes to the emergence of different management systems (MS), according to Dahlin and Isaksson (2017), Karapetrovic (2003) and Asif et al. (2011). In this sense, the integration of management systems is becoming increasingly popular as a solution to satisfy all stakeholders' objectives. An integrated system is beneficial for a company's efficiency, 
reducing its costs (Simon et al., 2012a). In a context with an increasing demand for the implementation of multiple management system standards, companies have two alternatives: to deal with individual systems separately or to integrate them. The second alternative may provide a greater corporate sustainability. The effect of the created synergy is a leaner system, without redundancies. The integration of systems allows companies to understand the stakeholders' needs and strive for business excellence (Asif et al., 2011; Karapetrovic, 2003, 2002).

For Bernardo et al. (2015) and Dahlin and Isaksson (2017), the integration process can be analysed through four aspects: strategy, implementation methodology, level of integration and integration of audit systems. In reference to strategy, it is necessary to define which management systems will be deployed and the sequence of this implementation. Bernardo et al. (2015) note that the system can be deployed simultaneously. Regarding the methodology, it is defined by the models and tools to be used. For the level of integration, it is necessary to determine if the systems will act independently, partially integrated or fully integrated. Finally, for audits, the possibility that these audits are evaluated jointly needs to be defined.

According to Bernardo et al. (2015) and the ISO Survey (ISO, 2019), ISO 9001 and ISO 14001 are the most implemented certificates in the world. Together they were responsible for approximately $90 \%$ of the ISO certificates issued in the world in 2018 (ISO, 2019). These management systems present many similarities in terms of structure and dissemination process, since both are based on the PDCA Cycle and follow the Annex SL guidelines (Nunhes et al., 2016; Wilson and Campbell, 2018). These similarities facilitate their integration (Bernardo et al., 2015).

For Rebelo et al. (2015), Domingues et al. (2016) and Rebelo et al. (2016), the separate use of multiple management systems within companies is a poor approach that contradicts the best practices guidelines. They argue that the integration of multiple management systems with a holistic vision, besides supporting value creation, strengthens the sustainable development of organizations.

When evaluating the publications about IMS on the last twenty years, a recent study (Nunhes et al., 2016) identified five main groups of subjects: (i) IMS and sustainability; (ii) IMS, strategy, performance and innovation; (iii) IMS and Social Responsibility; (iv) evaluation of the integration levels, motivations, benefits and 
difficulties of IMS, and (v) methods, guidelines and maturity levels of IMS. The papers presented in the following paragraphs may be allocated into these categories.

A methodology to integrate different management systems was presented by Rebelo et al. (2015). After searching for procedures and documented processes common to different management systems, they identified common areas and requirements versus similarities to support their methodology. The authors point out that their methodology can be used to integrate different management systems, since it was structured based on PDCA fundamentals.

Gianni and Gotzamani (2015) emphasize that an IMS should contain all of the requirements stipulated by the standards implemented in order for the organization to enjoy all the benefits. The same authors, however, point out the absence of a globally recognized standard for the integration process and, in this way, they propose a step-bystep methodology to get an IMS. The steps are: (i) process mapping; (ii) documentation; (iii) training; (iv) internal audits; (v) administrative review or management review; (vi) corrective and preventive actions; (vii) external audits and (viii) certification.

A proposal to analyse the integration maturity in a six-level model is presented by Domingues et al. (2016). The model titled IMS-MMC presents three natural aspects which consider process agents, pillars and externalities (process agents: key process and kpa; pillars: focus, leadership, involvement, process approach, systemic approach, continuous improvement, decision based on evidence and mutual benefit relations; externalities: macro ergonomics, life cycle analysis, sustainable development and social responsibility).

Cases of success regarding IMS are also presented in the literature. Anholon et al. (2016) analysed the "fully integrated" IMS from Embraer, in Brazil. According to the authors, the focused company integrated ISO 9001, ISO 14001, OHSAS 18001, ISO 26001 and SA8000. Among the benefits obtained, the optimization in the use of several resources and employees' motivation can be highlighted.

Analysing the reasons for companies to purposefully implement their management systems separately, Chountalas and Tepaskoualos (2019) verified that a construction company they analysed opted to do not integrate them in order to maintain a balance among executives power and focus individually in each area. However, authors 
highlight the need for the company to stimulate cooperation among its executives at least towards a partial integration, to obtain gains with the benefits provided by IMS.

Despite the mentioned benefits, organizations face great challenges during the process to integrate their management systems. The most commonly cited difficulties are lack of resources, especially human resources, lack of government support, internal problems and individual concerns of the people involved. In addition, lack of employee motivation and differences among standards are also mentioned (Simon et al., 2012a; Simon and Douglas, 2013).

For Sampaio et al. (2012) and Nunhes et al. (2016), the difficulties are associated with costs, managerial complexity, quantity of resources required, level of bureaucracy, lack of adequate methodology, resistance to organizational changes, lack of commitment, lack of employee involvement and cultural incompatibility. Siva et al. (2016) also mention inappropriate timing and large differences in models that support standards. It is interesting to notice that several difficulties for IMS are also observed when companies are implementing QMS (Anholon et al., 2018).

Rebelo et al. (2015) also list the main problems observed during the integration process: (i) lack of human and material resources; (ii) resistance to change; (iii) complex organizational structure; (iv) diversity of products or services; (v) absence of a guideline to support the implementation process and absence of an explicit goal; (vi) lack of internal competence in system integration; (vii) lack of an international standard.Besides the above-mentioned difficulties, it is important to emphasize that a true integration of management systems provides several benefits, as discussed in the next section. The integration of management systems enables synergy gains through the execution of common tasks, generating internal cohesion and costs reduction, better objectives alignment, improvement of processes and reduction of bureaucracy with documentation. Other benefits include multifunctional work, reductions in internal and external audits, better systems performance, improvement of the company's image, better communication, and improved employee motivation, thereby implying benefits for several stakeholders (Čekanová, 2015; de Oliveira, 2013; Eriksson and Hansson, 2006; Gianni and Gotzamani, 2015; José Tarí and Molina-Azorín, 2010; Simon et al., 2012a).

Sampaio et al. (2012) also agree, highlighting reasons for integration: it enables the aligned treatment among quality, environmental, ethics and organizational 
profitability aspects; it reduces redundancies, increases efficiency, reduces costs, and reduces audits; finally, it enables the development of a management system that includes the sustainability concept.

Bernardo et al. (2015) presented an extensive literature review and summarized the benefits generated by the integration of ISO 9001 and ISO 14001. These benefits are classified as internal and external, a classification reinforced by José Tarí and MolinaAzorín (2010). In Table 1 we organize the benefits pointed out by Bernardo et al. (2015).

Table 1. Benefits generated by the integration of ISO 9001 and ISO 14001. Source: Adapted from Bernardo et al. (2015, p. 263)

\begin{tabular}{|c|c|}
\hline \multirow{18}{*}{ 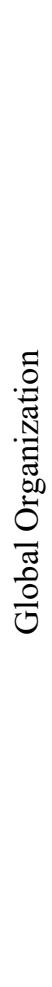 } & Integration contributes to improve organizational efficiency. \\
\hline & Integration contributes to simplify the tasks. \\
\hline & Integration optimizes the use of financial and human resources through a single goal. \\
\hline & Integration allows the reduction of management costs. \\
\hline & Integration creates an organization that is constantly improving. \\
\hline & Integration provides time savings of different resources. \\
\hline & $\begin{array}{l}\text { Integration promotes the elimination of barriers and better collaboration between } \\
\text { departments. }\end{array}$ \\
\hline & Integration contributes to a continuous work of excellence. \\
\hline & Integration facilitates the decision-making process. \\
\hline & Integration enhance our ability to achieve goals. \\
\hline & Integration contributes to the definition of the organizational strategy. \\
\hline & Integration eliminates conflicts between different strategies. \\
\hline & Integration supports the common policies, objectives, goals and performance indicators. \\
\hline & Integration makes the communication process clearer. \\
\hline & Integration promotes improvements in organizational culture. \\
\hline & Integration allows a better risk management analysis. \\
\hline & Integration is seen as a competitive advantage for the business sector. \\
\hline & Integration makes easier comply the legislation. \\
\hline \multirow{6}{*}{ 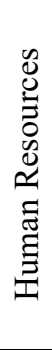 } & Integration enhances the qualification of our professionals. \\
\hline & Integration optimizes training activities. \\
\hline & $\begin{array}{l}\text { Integration makes the employees recognize the importance of their work for the organization } \\
\text { objectives. }\end{array}$ \\
\hline & Integration contributes to teamwork. \\
\hline & Integration enhances the employees' skills. \\
\hline & Integration has a positive impact on people's motivation. \\
\hline \multirow{5}{*}{ 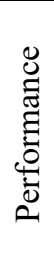 } & Integration improves the organization's performance. \\
\hline & Integration improves the quality of products or services. \\
\hline & Integration increases organizational productivity. \\
\hline & Integration has a positive impact on the products reliability and processes. \\
\hline & Integration becomes the feedback process to clients better. \\
\hline
\end{tabular}




\begin{tabular}{|c|c|}
\hline \multirow{8}{*}{$\sum_{\Sigma}^{\infty}$} & Integration works as a solution to reduce duplication of policies, procedures and records. \\
\hline & Integration ensures agility and less redundancy to daily management. \\
\hline & $\begin{array}{l}\text { Integration simplifies individual management systems, promoting lower confusion, } \\
\text { redundancy and documentation conflict. }\end{array}$ \\
\hline & Integration reduces bureaucracy. \\
\hline & Integration eliminates conflicts between individual management systems. \\
\hline & Integration contributes to the better understanding and application of management systems. \\
\hline & Integration brings flexibility to standards. \\
\hline & Integration helps to define the responsibilities and authorities. \\
\hline \multirow{5}{*}{ 导 } & Integration unifies/reduces internal audits. \\
\hline & Integration reduces the internal audits costs. \\
\hline & Integration simplifies audit process. \\
\hline & Integration promotes better use of audits results. \\
\hline & Integration supports the reduction of multiple audits. \\
\hline \multirow{4}{*}{ 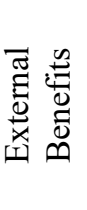 } & Integration contributes to improving the organization's image. \\
\hline & Integration represents a way to ensure sustainability within a global market context. \\
\hline & Integration allows to improve partnership relations and the stakeholders' satisfaction. \\
\hline & Integration contributes to better external audits results. \\
\hline
\end{tabular}

\section{Methodological Procedures}

This section presents information to enable the replication of the study's procedures by other researchers. The phases developed were: 1) literature review to establish the theoretical background used in the research; 2) case study (part 1) in the tire manufacturer to provide more information about the management systems implemented; 3) research protocol development to be used in structured interviews with three managers of the company, considering 12 benefits presented by Bernardo et al. (2015) and the interviews conducted (case study - part 2); 4) data analysis; 5) conclusions about the management systems integration level; 6) proposition of the guidelines for the company and suggestion of a guide. Figure 1 show theses phases. 


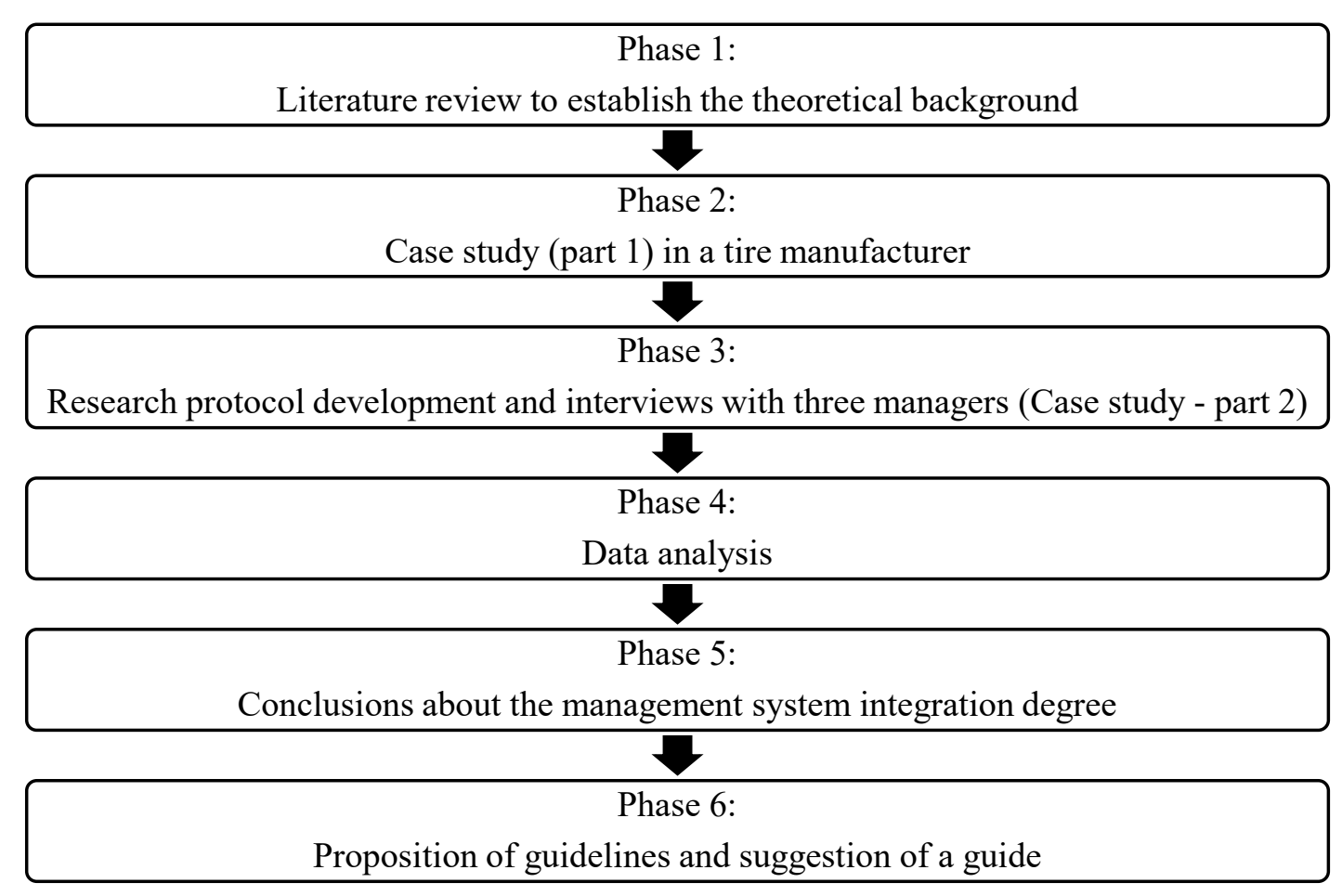

Figure 1. Phases developed in the research. Source: Authors.

The literature review was used to establish the conceptual basis about IMS. The terms used to find the articles were "integrated management systems", "integration of systems", "Management systems integration", "Multiple certifications", and "ISO 9001 + ISO 14001" associated to the terms "benefits", "advantages", "difficulties". Additionally, the term "multicriteria decision technique" was used to know more about data analysis. The scientific databases consulted were Emerald, Taylor \& Francis Online, Science Direct, Scopus and Periodical Capes (a Brazilian base). Since the benefits generated by the integration of quality management and environmental management systems are the focus of the analysis, a special attention was given to this theme.

After establishing the theoretical foundation, a case study was carried out in order to better understand some activities related to management systems in the company. For this, we conducted visits and a documentary analysis. This characterized the first part of the case study. Subsequently, the second part of case study was conducted, for triangulation purpose, as recommended by Yin (2014). In this phase, we structured a research protocol and conducted interviews with 3 professionals that work in the company and have extensive experience in management systems. The interviewee "A" was a quality manager in the company and currently works with process improvements. He has 
30 years of experience. The interviewee " $\mathrm{B}$ " is a management systems auditor and has 20 years of experience. Finally, the interviewee "C" is a quality manager of the company with 15 years of experience.

For the research protocol, 12 benefits were selected from those presented by Bernardo et al. (2015), as shown in Table 2. The difference of items between Table 1 and Table 2 are due to the summarization performed. For example, the items "Integration unifies/reduces internal audits", "Integration reduces the internal audits costs", "Integration simplifies audit process", "Integration promotes better use of audits results", and "Integration supports the reduction of multiple audits". (from Table 1) were summarized in the item "Integration unifies/reduces internal audits" (in Table 2). This reduction was performed due to the objective of the evaluation conducted. To obtain a ranking of the benefits, the position of a generic item related with internal audits was more relevant than specific positions of each detailed benefit regarding internal audit.

Table 2. Selected benefits used in protocol research. Source: Adapted from Bernardo et al. (2015).

\begin{tabular}{cl}
\hline Code & \multicolumn{1}{c}{ Benefits } \\
\hline B1 & Integration contributes to simplify the tasks. \\
B2 & Integration contributes to a continuous work of excellence. \\
B3 & Integration facilitates the decision-making process. \\
B4 & Integration makes the communication process clearer. \\
B5 & Integration allows a better risk management analyzes. \\
B6 & Integration enhances the qualification of our professionals. \\
B7 & Integration becomes the feedback process to clients better. \\
B8 & Integration simplifies individual management systems, promoting lower confusion, redundancy \\
B9 & Ind documentation conflict. \\
B10 & Integration contributes to the better understanding and application of management systems. \\
B11 & Integration unifies/reduces internal audits. \\
B12 & Integration contributes to better external audits results. \\
\hline
\end{tabular}

For each benefit, the interviewees presented their perception and chose a score from 1 to 5 , in which score 1 indicated a non-observation of the benefit in the company and score 5 indicated an intense observation of the benefit in the company, due to the integration of quality and environmental management systems.

The collected data were tabulated and analysed through Technique for Order of Preference by Similarity to Ideal Solution (TOPSIS). The used of TOPSIS enabled the 
synthetization of professionals' perception and the rank of observed benefits. The answers were weighted according to the interviewees' experience. These weights were defined by 3 specialists ( $\mathrm{PhD}$ in management), as follows: 50\% for interviewee "A"; 30\% for interviewee "B" and, finally, 20\% for interviewee "C". In this sense, the responses from more experienced respondents received a higher weight than responses from less experienced ones. Data ordering via TOPSIS followed the eight steps used by Singh et al. (2016). The eight steps are described in the following paragraphs.

Step 1: Data were tabulated by group according to the experts' panel considerations and the arithmetic means were calculated for each benefit in the groups.

Step 2: Matrix D was structured with the arithmetic means calculated in Step 1. The mathematical representation for matrix D is shown by Matrix 1 .

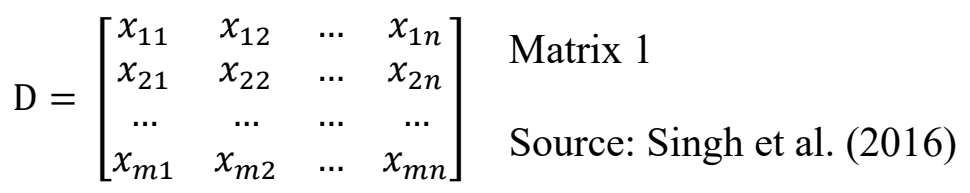

Step 3: The Matrix D was normalized through the calculation of rij coefficients. The mathematical representation to rij coefficients is presented by Equation 1. The result of this step is shown in Matrix 2.

$$
\begin{array}{ccl}
r_{i j}=x_{i j} / \sqrt{\sum_{i=1}^{n} x_{i j}^{2}} & & \text { Equation 1 } \\
\mathrm{R} & \left.\begin{array}{cccc}
r_{11} & r_{12} & \ldots & r_{1 n} \\
r_{21} & r_{22} & \ldots & r_{2 n} \\
\ldots & \ldots & \ldots & \ldots \\
r_{m 1} & r_{m 2} & \ldots & r_{m n}
\end{array}\right] & \text { Matrix 2 } \\
& \text { Source: Singh et al. (2016) }
\end{array}
$$

Step 4: Using the weights (wj) defined by panel experts for each professional group and Equation 2, the vij coefficients were calculated and, in the sequence, six Vi matrices were generated. See the mathematical representation in Matrix 3. 


$$
\begin{aligned}
& v_{i j}=w_{j} r_{i j} \\
& \text { Equation } 2 \\
& \text { Source: Singh et al. (2016) } \\
& \mathrm{V}=\left[\begin{array}{cccc}
v_{11} & v_{12} & \ldots & v_{1 n} \\
v_{21} & v_{22} & \ldots & v_{2 n} \\
\ldots & \ldots & \ldots & \ldots \\
v_{m 1} & v_{m 2} & \ldots & v_{m n}
\end{array}\right] \quad \text { Source: Singh et al. (2016) }
\end{aligned}
$$

Step 5: The ideal positive solution $(v j+)$ and the ideal negative solution (vj-) for each theme were defined (Equations 3 and 4). The ideal positive solution is characterized by the higher values of the means observed in the groups 3, 2 and 1. Likewise, the ideal negative solution is characterized by the lower values of the means observed in each group.

$$
v j+=\{\text { MAXjvij } \mid j=1,2, \ldots . . m\} \quad \begin{aligned}
& \text { Equation } 3 \\
& \text { Source: Singh et al. (2016) }
\end{aligned}
$$

\section{Equation 3}

$$
\text { vj- }=\{\text { MINjvij } \mid \mathrm{j}=1,2, \ldots . . \mathrm{m}\}
$$

\section{Equation 4}

Source: Singh et al. (2016)

Step 6: The positive ( $\left.\mathrm{Si}^{*}\right)$ and negative ( $\left.\mathrm{Si}^{\prime}\right)$ Euclidean distance for each benefit in each theme were calculated through Equations 5 and 6.

$$
\begin{array}{ll}
s_{i}^{*}=\left[\sum_{j}\left(v_{i j}^{*}-v_{j}^{+}\right)^{2}\right]^{1 / 2} & \begin{array}{l}
\text { Equation 5 } \\
\text { Source: Singh et al. (2016) }
\end{array} \\
s_{i}^{\prime}=\left[\sum_{j}\left(v_{i j}^{\prime}-v_{j}^{-}\right)^{2}\right]^{1 / 2} & \text { Equation 6 } \\
\text { Source: Singh et al. (2016) }
\end{array}
$$


Step 7: For each benefit in each theme, equation 7 was used to calculate the indicator $\mathrm{Ci}^{*}$. It is important to point out that $\mathrm{Ci}^{*}$ values range from 0 to 1.0 .

$$
c_{i}^{*}=\frac{s_{i}^{\prime}}{\left(s_{i}^{*}+s_{i}^{\prime}\right)} \quad \text { Equation } 7
$$

Source: Singh et al. (2016)

Step 8: The benefits within each theme were order according to $\mathrm{Ci}^{*}$ values obtained. Higher $\mathrm{Ci}^{*}$ values indicate better results.

Considering the findings gathered in the previous phases and information from the literature, it was possible to establish conclusions about the integration level of the ISO 9001 and ISO 14001 systems in the tire company and suggest a guide.

\section{Results and debates}

\subsection{Results from case study}

The company analysed is one of the leaders in the tire segment and has over 100 years of history. Currently, the company has more than 60 industrial units and 100,000 employees worldwide. It operates in Brazil since 1981. Currently, it has two industrial complexes in Brazil which produce tires for trucks, passenger cars, mining and agricultural machinery, among others. The first ISO 9001 and ISO 14001 certifications were implemented in 1997 and 1998, respectively. The company also has other specific certifications related to markets and/or countries in which it operates.

Regarding its QMS and EMS, there was an integration attempt once, but it was not successful. Presently, it is possible to observe that the integration level is quite incipient or simple, being perceived only in a few aspects or details. The following paragraphs present some characteristics of the company's reality that allow a better understanding of this level characterization.

\section{a) Quality and environmental policies and objectives}

The quality policy of the company is defined globally, and it is unique to all organizations. In turn, the environmental policy is defined for each site of the company and it is 
associated with municipality or state legislation. Then, it is possible to see that the policies are separated and have great potential to be integrated, serving as guidelines to all the company's employees. The same is true for the objectives; they are not defined in an integrated way.

\section{b) Document control}

The company has a single platform to manage all types of documents, such as manuals, procedures and work instructions. This is a positive aspect for the integration. Rules for reviews, approval, archiving and retention of documents are the same for both systems. In addition, the elaboration of some documents needs the requirements of both systems. It is not possible to state, however, that the document control is fully integrated. An example of this can be observed in manual elaborations, since the company decided to remain them separated. It is important to highlight that the company maintains manuals even though they are no longer mandatory according to 2015 version of the standards.

\section{c) Conducting audits}

The audits are performed totally independently. They are not conducted at the same time, and they have different teams. The trainings of the auditors are performed externally; these trainings are specific and are conducted for each management system of the company. Results from audit processes are critically analysed by top management in a separate process. Considering this information, it is evident that there is no integration in audit processes.

\section{d) Communication processes}

The company's communications regarding the management systems uses common tools such as bulletin boards, intranet pages, newsletters and digital dashboards. All information associated with quality and environmental management systems, however, is generated independently. For example, sometimes similar information is communicated twice because of the independence between the company's management systems. The communication team tries to ensure a consistent language in terms of content and image. It is noteworthy that the EMS defines communication types, deadlines and stakeholders involved. This is not observed in the QMS. 


\section{e) Assignment of responsibilities}

The attribution of responsibilities in the quality and environmental management systems is segregated and there is no integration regarding human resources. The QMS is controlled by the quality assurance department. In turn, the EMS is controlled by a central area that defines activities related to them.

\section{f) Continuous improvement}

The continuous improvement projects associated with management systems presently in the company are carried out independently in most of the cases, with few integrated activities. It is important to highlight that the processes of continuous improvement require financial resources, which have their implementation needs debated in planning meetings of the top management. Thus, in the meetings mentioned, continuous improvement projects are discussed together.

\subsection{Results from TOPSIS}

In order to gain further information about the integration level of the QMS and EMS, the authors of this article carried out interviews with three professionals of the tire company that have an extensive experience with the theme. Following the steps presented in section 3 , the answers of the three interviewees were initially tabulated as shown in Table 3. 
Table 3. Answers of the interviewees to the each benefits. Source: Authors.

\begin{tabular}{cccc}
\hline Benefits & Interviewee “A" & Interviewee "B" & Interviewee “C" \\
\hline B1 & 2 & 1 & 3 \\
B2 & 2 & 2 & 2 \\
B3 & 1 & 2 & 3 \\
B4 & 1 & 1 & 3 \\
B5 & 1 & 2 & 3 \\
B6 & 1 & 2 & 2 \\
B7 & 1 & 1 & 3 \\
B8 & 2 & 1 & 3 \\
B9 & 1 & 1 & 2 \\
B10 & 1 & 2 & 3 \\
B11 & 1 & 1 & 1 \\
B12 & 1 & 1 & 2 \\
\hline
\end{tabular}

After, we obtained the normalized and weighted matrix V, as shown in Table 4.

Table 4. Matrix "V" of normalized and weighted answers. Source: Authors.

\begin{tabular}{cccc}
\hline Benefits & Interviewee “A" & Interviewee "B" & Interviewee "C" \\
\hline B1 & 0.21821789 & 0.057735027 & 0.067082039 \\
B2 & 0.21821789 & 0.115470054 & 0.04472136 \\
B3 & 0.109108945 & 0.115470054 & 0.067082039 \\
B4 & 0.109108945 & 0.057735027 & 0.067082039 \\
B5 & 0.109108945 & 0.115470054 & 0.067082039 \\
B6 & 0.109108945 & 0.115470054 & 0.04472136 \\
B7 & 0.109108945 & 0.057735027 & 0.067082039 \\
B8 & 0.21821789 & 0.057735027 & 0.067082039 \\
B9 & 0.109108945 & 0.057735027 & 0.04472136 \\
B10 & 0.109108945 & 0.115470054 & 0.067082039 \\
B11 & 0.109108945 & 0.057735027 & 0.02236068 \\
B12 & 0.109108945 & 0.057735027 & 0.04472136 \\
\hline
\end{tabular}

The following step was characterized by the determination of the positive and negative ideal solutions, indicated in Table 5.

Table 5. Positive and Negative ideal solutions. Source: Authors.

\begin{tabular}{cccc}
\hline Ideal solution & Interviewee “A” & Interviewee "B" & Interviewee "C" \\
\hline Positive ideal solution $\left(v_{j}^{+}\right)$ & 0.21821789 & 0.11547005 & 0.06708204 \\
Negative ideal solution $\left(v_{j}^{-}\right)$ & 0.109108945 & 0.05773503 & 0.02236068 \\
\hline
\end{tabular}


Subsequently, the Euclidean distances of each value presented in Table 4 were calculated in relation to the positive and negative ideal solutions (Table 5), using Equations 5 and 6 . With the Euclidean distances defined, it was possible to calculate the coefficients $\mathrm{Ci}$ * using Equation 7. The coefficients $\mathrm{Ci}^{*}$ allowed the comparison among the studied benefits. Table 6 presents the Euclidean distances calculated, the $\mathrm{Ci}^{*}$ coefficients.

Table 6. Euclidean distances, $\mathrm{Ci}$ * coefficient and the final ranking. Source: Authors.

\begin{tabular}{cccc}
\hline Benefits & Distance Positive Ideal Solution $\left(\mathrm{Si}^{*}\right)$ & Distance Negative Ideal Solution $\left(\mathrm{Si}^{\prime}\right)$ & $\mathrm{Ci}^{*}$ \\
\hline B1 & 0.057735027 & 0.117918454 & 0.671313 \\
B2 & 0.02236068 & 0.125451565 & 0.848722 \\
B3 & 0.109108945 & 0.073029674 & 0.400957 \\
B4 & 0.12344268 & 0.04472136 & 0.265939 \\
B5 & 0.109108945 & 0.073029674 & 0.400957 \\
B6 & 0.111376667 & 0.061913919 & 0.357284 \\
B7 & 0.12344268 & 0.04472136 & 0.265939 \\
B8 & 0.057735027 & 0.117918454 & 0.671313 \\
B9 & 0.125451565 & 0.02236068 & 0.151278 \\
B10 & 0.109108945 & 0.073029674 & 0.400957 \\
B11 & 0.131293927 & 0 & 0 \\
B12 & 0.125451565 & 0.02236068 & 0.151278 \\
\hline
\end{tabular}

Table 7 shows the final comparative ordering of the benefits ranked through $\mathrm{Ci}^{*}$ values.

Table 7. Final ranking of the benefits. Source: Authors.

\begin{tabular}{|c|c|c|c|}
\hline Ranking & $\mathbf{C i} *$ & Benefits & Benefits description \\
\hline $1^{\circ}$ & 0.848722 & $\mathrm{~B} 2$ & Integration contributes to a continuous work of excellence. \\
\hline $2^{\circ}$ & 0.671313 & B1 & Integration contributes to simplify the tasks. \\
\hline $3^{\circ}$ & 0.671313 & B8 & $\begin{array}{l}\text { Integration simplifies individual management systems, promoting } \\
\text { lower confusion, redundancy and documentation conflict. }\end{array}$ \\
\hline $4^{\circ}$ & 0.400957 & B3 & Integration facilitates the decision-making process. \\
\hline $5^{\circ}$ & 0.400957 & B5 & Integration allows a better risk management analyzes. \\
\hline $6^{\mathrm{o}}$ & 0.400957 & $\mathrm{~B} 10$ & Integration helps to define the responsibilities and authorities. \\
\hline $7^{\circ}$ & 0.357284 & B6 & Integration enhances the qualification of our professionals. \\
\hline $8^{\circ}$ & 0.265939 & B4 & Integration makes the communication process clearer. \\
\hline $9^{\circ}$ & 0.265939 & B7 & Integration becomes the feedback process to clients better. \\
\hline $10^{\circ}$ & 0.151278 & B9 & $\begin{array}{l}\text { Integration contributes to the better understanding and application of } \\
\text { management systems. }\end{array}$ \\
\hline $11^{\mathrm{o}}$ & 0.151278 & B12 & Integration contributes to better external audits results. \\
\hline $12^{\circ}$ & 0 & B11 & Integration unifies/reduces internal audits. \\
\hline
\end{tabular}


Analysing the scores measured by the interviewees (Table 3) and the ranking obtained via TOPSIS, it is possible to verify that the tire company has an incipient integration level of the management systems. When considering the study of Bernardo et al. (2009), which presents maturity levels for management systems integration, it is possible to affirm that the tire company has an integration level ranging from 0 to 1 , since there are few benefits perceived by the three interviewed professionals. When analysed comparatively, the benefits that present better scores are B2, B1 and B8. However, it is important to mention that they have low scores. This result is consistent with the information gathered through the case study conducted.

\subsection{Guidelines for the integration of management systems in the tire manufacturer}

Regarding the integration model to be adopted and, consequently, the strategy to be used, the academic literature presents different options (Bernardo et al., 2015, 2012, 2009; Karapetrovic and Casadesús, 2009; Zeng et al., 2007). After a detailed analysis of the models mentioned above, the authors considered the recommendations proposed by Karapetrovic (2002), Karapetrovic (2003) and Bernardo et al. (2009) as the models that could better support these guidelines.

Analyzing the results obtained, it is possible to affirm that the full integration of the management systems is not a good option for the tire company, since it is not prepared for this. Then, the first guideline proposed is: "to opt for a partial integration process, following information presented in Karapetrovic (2002) and Karapetrovic (2003), rather than a full integration attempt". After some time and following the PDCA philosophy, the company can analyse the new integration maturity level and consider the possibility of a full integration.

It is recommended that the tire manufacturer initiates the partial integration mentioned by an "aligning of the quality and environment policies, because this action will provide broad and unique values for all company employees". This also needs to be done with quality and environment goals, since a strong policy and well-defined goals may be used as macro guiding.

The next guideline is characterized by the "unification of activities that present at least a minimal sign of integration". These activities are: continuous improvement, document control and communication processes. The idea is to potentialize the existing 
benefits and use them to motivate employees. After obtaining better results in these activities, it is possible to perform a new evaluation of the benefits provided by integration and decide to integrate other activities or deepen the mentioned ones. At the same time, we recommend to "identify processes that are separate, but have great integration potential, such as records control, determination of stakeholder requirements, product operations, management review and planning".

Regarding the maturity of the activities, we considered that "internal audits, preventive and corrective actions and nonconformities control need to be improved in each management system before the integration. Then, we don't recommend the integration of these activities initially". As mentioned earlier, this can be done in the future.

For many authors, the integration of human resources is characterized as a natural and relevant path (de Oliveira, 2013; Karapetrovic, 2002; Simon et al., 2012a, 2012b; Zeng et al., 2007). We agree with this statement, but analysing the company studied, it is possible to observe that it is not yet prepared for this. Then, "we recommend that it [sic] does not integrate human resources initially".

\subsection{Lessons Learned Throughout the Study and Suggested Guide}

The development of the study in the tire company made it possible to learn some lessons. The first lesson learned is that professionals who work in the company can greatly contribute to the correct definition of the integration level evaluation. Based on their experience, perceptions can be collected and contribute to better results. The use of the 12 benefits listed from the study of Bernardo et al. (2015) in the interview process also proved to be a correct decision, since it reduces the number of items to be evaluated without considerable loss of content.

It is important to highlight the results provided by the combination of case study and TOPSIS analysis for interviews responses. The use of the two techniques made it possible to compare data and better determine the actual integration level of the company's activities. For this case study, a detailed analysis of policies, objectives, document control, auditing processes, communication level, attribution of responsibilities and continuous improvement processes provided useful findings. 
Another interesting lesson learned and aligned with the considerations of Karapetrovic (2002), Karapetrovic (2003) and Bernardo et al. (2009) is that a multicertified company is not necessarily prepared for a full integration of its management systems. Sometimes, it is better to opt for a partial integration, aiming for some positive results before deciding for a full integration of the management systems. In short, the fact that the company has certifications does not mean that it has the maturity to integrate the management activities.

From the information and lessons learned that we have presented, we suggest a guide that combines theories and can be used by companies to evaluate the integration level of their quality and environmental management systems. Of course, this suggestion is made on an exploratory level, since the guide needs to be used by other companies in order to verify its validity. Figure 2 presents the suggested guide.

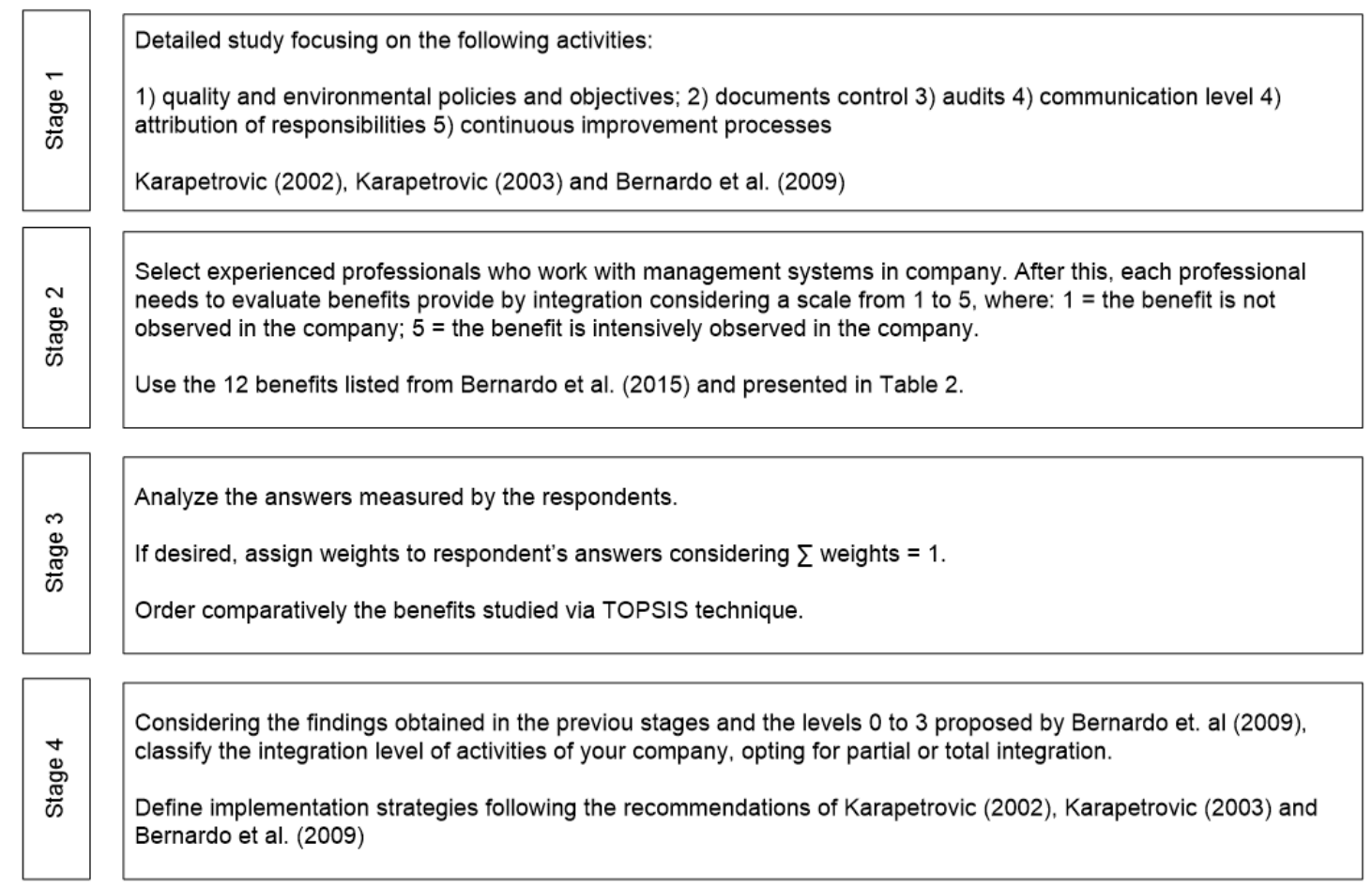

Figure 2. Suggested guide. Source: structured from Karapetrovic (2002), Karapetrovic (2003) and Bernardo et al. (2009)

\section{Conclusion}

The integration of management systems has positive effects on companies, but it is not a 
simple activity. Analysis of the existing integration level helps managers to make better decisions. The main objective of this paper was to evaluate the integration level of the QMS and EMS system in a tire manufacturing company. Additionally, using the information from the literature and the lessons learned, a guide was suggested in an exploratory way. Based on the results obtained, it is possible to verify that the objective of this research was achieved.

For the tire manufacturer analysed, the conclusion is that the integration of the management systems is very simple. In this sense, a partial integration considering some well-defined actions seems to be the logical path. The activities developed in this study, contemplating qualitative and quantitative techniques, provided interesting results and some important lessons. Using these findings, we suggest a guide in an exploratory way to be used by other companies that aim to integrate their management systems.

The information presented in this article can be useful for other companies that wish to evaluate the integration of QMSs and EMSs. Professionals of these companies can use the same structure presented here (list of benefits identified by Bernardo et al. (2015), forms, interviews, structures and TOPSIS technique) to evaluate the integration level and propose guidelines for different realities.

Two results from this research can be mentioned as main contributions: The case study of a large tire manufacturing that, although have implemented QMS and EMS, do not have enough maturity to perform a full integration of its management systems; the second contribution is the guide that can be used by future researchers as a starting point for proposing new administrative tools and can also be used as a framework for other companies from different sectors and, later, for the comparison of results.

The study limitations should also be mentioned. The use of professionals' opinions to evaluate the benefits limits the analysis to respondents' perception. However, the use of TOPSIS minimizes the bias since it attributes a greater weight for more experienced professionals. Additionally, the use of responses from a group of professionals also contribute to minimize the risks associated with individual perceptions.

\section{Note}

To be inserted after blind review. 


\section{Acknowledgment}

They will be inserted after the review process.

\section{References}

Anholon, R., Quelhas, O.L.G., Leal Filho, W., de Souza Pinto, J., Feher, A., 2016. Assessing corporate social responsibility concepts used by a Brazilian manufacturer of airplanes: A case study at Embraer. J. Clean. Prod. 135, 740-749. https://doi.org/10.1016/j.jclepro.2016.06.169

Anholon, R., Simon Rampasso, I., Cooper Ordonez, R.E., Silva, D. da, Quelhas, O.L.G., Leal Filho, W., 2018. Observed difficulties during implementation of quality management systems in Brazilian manufacturing companies. J. Manuf. Technol. Manag. 29, 149-167. https://doi.org/10.1108/JMTM-12-2016-0167

Asif, M., Searcy, C., Zutshi, A., Ahmad, N., 2011. An integrated management systems approach to corporate sustainability. Eur. Bus. Rev. 23, 353-367. https://doi.org/10.1108/09555341111145744

Bernardo, M., Casadesus, M., Karapetrovic, S., Heras, I., 2012. Integration of standardized management systems: does the implementation order matter? Int. J. Oper. Prod. Manag. 32, 291-307. https://doi.org/10.1108/01443571211212583

Bernardo, M., Casadesus, M., Karapetrovic, S., Heras, I., 2010. An empirical study on the integration of management system audits. J. Clean. Prod. 18, 486-495. https://doi.org/10.1016/j.jclepro.2009.12.001

Bernardo, M., Casadesus, M., Karapetrovic, S., Heras, I., 2009. How integrated are environmental, quality and other standardized management systems? An empirical study. J. Clean. Prod. 17, 742-750. https://doi.org/10.1016/j.jclepro.2008.11.003

Bernardo, M., Simon, A., Tarí, J.J., Molina-Azorín, J.F., 2015. Benefits of management systems integration: a literature review. J. Clean. Prod. 94, 260-267. https://doi.org/10.1016/j.jclepro.2015.01.075

Blasco-Torregrosa, M., Perez-Bernabeu, E., Palacios-Guillem, M., Gisbert-Soler, V., 2019. How do firms integrate management systems? A comparative study. Total Qual. Manag. Bus. Excell. 0, 1-17. 
https://doi.org/10.1080/14783363.2019.1635447

Borges, M.L., Anholon, R., Cooper Ordoñez, R.E., Quelhas, O.L.G., Santa-Eulalia, L.., Leal Filho, W., 2018. Corporate Social Responsibility (CSR) practices developed by Brazilian companies: an exploratory study. Int. J. Sustain. Dev. World Ecol. 25, 509-517. https://doi.org/10.1080/13504509.2017.1416700

Cabecinhas, M., Domingues, P., Sampaio, P., Bernardo, M., Franceschini, F., Galetto, M., Gianni, M., Gotzamani, K., Mastrogiacomo, L., Hernandez-Vivanco, A., 2018. Integrated management systems diffusion models in South European countries. Int. J. Qual. Reliab. Manag. 35, 2289-2303. https://doi.org/10.1108/IJQRM-03-20170044

Casadesús, M., Karapetrovic, S., Heras, I., 2011. Synergies in standardized management systems: some empirical evidence. TQM J. 23, 73-86.

https://doi.org/10.1108/17542731111097506

Čekanová, K., 2015. Integrated Management System - Scope, Possibilities And Methodology. Res. Pap. Fac. Mater. Sci. Technol. Slovak Univ. Technol. 23, 135140. https://doi.org/10.1515/rput-2015-0016

Chountalas, P.T., Tepaskoualos, F.A., 2019. Selective integration of management systems: a case study in the construction industry. TQM J. 31, 12-27. https://doi.org/10.1108/TQM-03-2018-0028

Dahlin, G., Isaksson, R., 2017. Integrated management systems - interpretations, results, opportunities. TQM J. 29, 528-542. https://doi.org/10.1108/TQM-01-20160004

de Oliveira, O.J., 2013. Guidelines for the integration of certifiable management systems in industrial companies. J. Clean. Prod. 57, 124-133. https://doi.org/10.1016/j.jclepro.2013.06.037

Domingues, P., Sampaio, P., Arezes, P.M., 2016. Integrated management systems assessment: a maturity model proposal. J. Clean. Prod. 124, 164-174. https://doi.org/10.1016/j.jclepro.2016.02.103

Eriksson, H., Hansson, J., 2006. Integrated Management Systems - Theoretical and Practical Implications. Asian J. Qual. 7, 69-82. https://doi.org/10.1108/15982688200600017 
Gianni, M., Gotzamani, K., 2015. Management systems integration: lessons from an abandonment case. J. Clean. Prod. 86, 265-276. https://doi.org/10.1016/j.jclepro.2014.08.023

Gianni, M., Gotzamani, K., Tsiotras, G., 2017. Multiple perspectives on integrated management systems and corporate sustainability performance. J. Clean. Prod. 168, 1297-1311. https://doi.org/10.1016/j.jclepro.2017.09.061

Goyal, A., Agrawal, R., Saha, C.R., 2019. Quality management for sustainable manufacturing: Moving from number to impact of defects. J. Clean. Prod. 241, 118348. https://doi.org/10.1016/j.jclepro.2019.118348

Hamdoun, M., Chiappetta Jabbour, C.J., Ben Othman, H., 2018. Knowledge transfer and organizational innovation: Impacts of quality and environmental management. J. Clean. Prod. 193, 759-770. https://doi.org/10.1016/j.jclepro.2018.05.031

Hassan, N.A., Mohamad Zailani, S.H., Hasan, H.A., 2019. Integrated internal audit in management system. TQM J. 32, 110-126. https://doi.org/10.1108/TQM-03-20190077

Hernandez-Vivanco, A., Domingues, P., Sampaio, P., Bernardo, M., Cruz-Cázares, C., 2019. Do multiple certifications leverage firm performance? A dynamic approach. Int. J. Prod. Econ. 218, 386-399. https://doi.org/10.1016/j.ijpe.2019.07.016

Ikram, M., Sroufe, R., Zhang, Q., 2020. Prioritizing and overcoming barriers to integrated management system (IMS) implementation using AHP and G-TOPSIS. J. Clean. Prod. 254, 120121. https://doi.org/10.1016/j.jclepro.2020.120121

Ikram, M., Zhou, P., Shah, S.A.A., Liu, G.Q., 2019. Do environmental management systems help improve corporate sustainable development? Evidence from manufacturing companies in Pakistan. J. Clean. Prod. 226, 628-641. https://doi.org/10.1016/j.jclepro.2019.03.265

ISO, 2019. International Organization for Standardization [WWW Document]. URL https://www.iso.org/the-iso-survey.html (accessed 10.22.19).

José Tarí, J., Molina-Azorín, J.F., 2010. Integration of quality management and environmental management systems. TQM J. 22, 687-701. https://doi.org/10.1108/17542731011085348

Karapetrovic, S., 2003. Musings on integrated management systems. Meas. Bus. Excell. 
7, 4-13. https://doi.org/10.1108/13683040310466681

Karapetrovic, S., 2002. Strategies for the integration of management systems and standards. TQM Mag. 14, 61-67. https://doi.org/10.1108/09544780210414254

Karapetrovic, S., Casadesús, M., 2009. Implementing environmental with other standardized management systems: Scope, sequence, time and integration. J. Clean. Prod. 17, 533-540. https://doi.org/10.1016/j.jclepro.2008.09.006

Leal Filho, W., Manolas, E., Pace, P., 2015. The future we want: Key issues on sustainable development in higher education after Rio and the UN decade of education for sustainable development. Int. J. Sustain. High. Educ. 16, 112-129. https://doi.org/10.1108/IJSHE-03-2014-0036

Nunhes, T.V., Bernardo, M., Oliveira, O.J., 2019. Guiding principles of integrated management systems: Towards unifying a starting point for researchers and practitioners. J. Clean. Prod. 210, 977-993. https://doi.org/10.1016/j.jclepro.2018.11.066

Nunhes, T.V., Ferreira Motta, L.C., de Oliveira, O.J., 2016. Evolution of integrated management systems research on the Journal of Cleaner Production: Identification of contributions and gaps in the literature. J. Clean. Prod. 139, 1234-1244. https://doi.org/10.1016/j.jclepro.2016.08.159

Nunhes, T.V., Oliveira, O.J., 2018. Analysis of Integrated Management Systems research: identifying core themes and trends for future studies. Total Qual. Manag. Bus. Excell. 0, 1-23. https://doi.org/10.1080/14783363.2018.1471981

Rebelo, M., Santos, G., Silva, R., 2015. Integration of Standardized Management Systems: A Dilemma? Systems 3, 45-59. https://doi.org/10.3390/systems3020045

Rebelo, M.F., Santos, G., Silva, R., 2016. Integration of management systems: towards a sustained success and development of organizations. J. Clean. Prod. 127, 96-111. https://doi.org/10.1016/j.jclepro.2016.04.011

Salomone, R., 2008. Integrated management systems: experiences in Italian organizations. J. Clean. Prod. 16, 1786-1806. https://doi.org/10.1016/j.jclepro.2007.12.003

Sampaio, P., Saraiva, P., Domingues, P., 2012. Management systems: Integration or addition? Int. J. Qual. Reliab. Manag. 29, 402-424. 
https://doi.org/10.1108/02656711211224857

Shah, S.A.R., Jamaludin, K.R., Talib, H.H.A., Yusof, S.M., 2019. Integrated quality environmental management implementation in food processing SMEs. TQM J. 31, 740-757. https://doi.org/10.1108/TQM-11-2018-0166

Simon, A., Douglas, A., 2013. Integrating management systems: does the location matter? Int. J. Qual. Reliab. Manag. 30, 675-689. https://doi.org/10.1108/02656711311325629

Simon, A., Karapetrovic, S., Casadesus, M., 2012a. Evolution of Integrated Management Systems in Spanish firms. J. Clean. Prod. 23, 8-19. https://doi.org/10.1016/j.jclepro.2011.10.025

Simon, A., Karapetrovic, S., Casadesús, M., 2012b. Difficulties and benefits of integrated management systems. Ind. Manag. Data Syst. 112, 828-846. https://doi.org/10.1108/02635571211232406

Singh, R.K., Gupta, A., Kumar, A., Khan, T.A., 2016. Ranking of barriers for effective maintenance by using TOPSIS approach. J. Qual. Maint. Eng. 22, 18-34. https://doi.org/10.1108/JQME-02-2015-0009

Siva, V., Gremyr, I., Bergquist, B., Garvare, R., Zobel, T., Isaksson, R., 2016. The support of Quality Management to sustainable development: a literature review. J. Clean. Prod. 138, 148-157. https://doi.org/10.1016/j.jclepro.2016.01.020

Wilson, J.P., Campbell, L., 2018. ISO 9001:2015: the evolution and convergence of quality management and knowledge management for competitive advantage. Total Qual. Manag. Bus. Excell. 0, 1-16. https://doi.org/10.1080/14783363.2018.1445965

Yin, R.K., 2014. Case Study Research: Design and Methods, 5th ed. SAGE Publications, Inc., Thousand Oaks.

Zeng, S.X., Tian, P., Tam, C.M., 2007. Overcoming barriers to sustainable implementation of the ISO 9001 system. Manag. Audit. J. 22, 244-254. https://doi.org/10.1108/02686900710733125 